\title{
Interictal and Ictal MEG in presurgical evaluation for epilepsy surgery
}

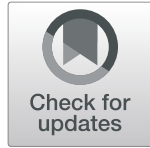

Hermann Stefan ${ }^{1 *}$ and Stefan Rampp ${ }^{2}$

\begin{abstract}
Although presurgical evaluation of patients with pharamacoresistent focal epilepsies provides essential information for successful epilepsy surgery, there is still a need for further improvement. Developments of noninvasive electrophysiological recording and analysis techniques offer additional information based on interictal and ictal epileptic activities. In this review, we provide an overview on the application of ictal magnetoencephalography (MEG). The results of a literature research for published interictal/ictal MEG findings and experiences with own cases are demonstrated and discussed. Ictal MEG may provide added value in comparison to interictal recordings. The results may be more focal and closer to the invasively determined seizure onset zone. In some patients without clear interictal findings, ictal MEG could provide correct localization. Novel recording and analysis techniques facilitate ictal recordings. However, extended recording durations, movement and artifacts still represent practical limitations. Ictal MEG may provide added value regarding the localization of the seizure onset zone but depends on the selection of patients and the application of optimal analysis techniques.
\end{abstract}

Keywords: Ictal MEG, Interictal MEG, Localization of epileptic activity, Presurgical evaluation

\section{Introduction}

Epilepsy surgery is an effective treatment option in drug resistant focal epilepsies. A meta-analysis of 78 studies with postoperative follow up (mean of 5 years) has demonstrated seizure control in $66 \%$ temporal lobe epilepsy and less in extra temporal lobe epilepsies [1]. A recent study pooling cases from 36 European centers reported an overall postoperative seizure freedom rate of $60.7 \%$ in 7168 patients [2]. This clearly underlines a need for improvement of presurgical evaluation, e.g. by extending the diagnostic spectrum. Magnetoencephalography (MEG) has been shown to significantly improve postoperative freedom rates $[3,4]$, even though the majority of MEG results rely on interictal epileptic activity. In the following, we review available literature on the added clinical value of ictal MEG for the presurgical evaluation of patients with focal epilepsies.

\footnotetext{
* Correspondence: hermann.stefan@t-online.de

'Department of Neurology - Biomagnetism, University Hospital Erlangen, 6, Schabachanlage, 91054 Erlangen, Germany

Full list of author information is available at the end of the article
}

\section{Interictal MEG}

The relation of interictal and ictal focal epileptic activity is an ongoing matter of debate for the use in presurgical evaluation. Interictal spikes of the so-called "irritative zone" can be widely distributed. Hufnagel et al. [5] have a analyzed the seizure-onset localizations by detecting interictal spikes using invasive long-term recordings, and identified the earliest averaged spikes of a spike cluster within zone of $<2 \mathrm{~cm}$ from the site of seizure onset in $84 \%(n=32)$ of patients. The question arises if ictal MEG can provide added value to interictal MEG.

MEG recordings usually last between 1 and $2 \mathrm{~h}$. According to the study of De Tiège et al. [6], the mean recording duration in European labs is $90 \mathrm{~min}$, due in a large part to logistical rather than technical reasons. During this time, the interictal epileptic activity is most oftenly detected. The interictal MEG localization corresponds to the invasive seizure onset in $71-100 \%$ [7-10].

If the analysis of interictal spikes shows monofocal dense clusters of source localizations and if these are taken into account for resection, postoperative seizure control is good $[11,12]$.

(c) The Author(s). 2020 Open Access This article is licensed under a Creative Commons Attribution 4.0 International License, which permits use, sharing, adaptation, distribution and reproduction in any medium or format, as long as you give appropriate credit to the original author(s) and the source, provide a link to the Creative Commons licence, and indicate if changes were made. The images or other third party material in this article are included in the article's Creative Commons licence, unless indicated otherwise in a credit line to the material. If material is not included in the article's Creative Commons licence and your intended use is not permitted by statutory regulation or exceeds the permitted use, you will need to obtain permission directly from the copyright holder. To view a copy of this licence, visit http://creativecommons.org/licenses/by/4.0/. 
In the study of $\mathrm{Mu}$ et al. [3] involving 46 patients with presurgical MEG evaluation and intractable frontal lobe epilepsy (FLE) surgery $47.9 \%$ became seizure free at a mean follow-up of $5.0 \pm 4.0$ years. Dipole clusters were completely resected in $70.9 \%$ of patients with monofocal activity and resulted in significantly higher seizure free rates compared to partial resection. Complete and extended lesionectomies showed an improved outcome to partial resection. Other studies evaluated resection of areas with increased connectivity based on the resting state network analysis, which showed correlations with postoperative seizure control $[13,14]$.

In many patients, localizing interictal MEG sources provides information for surgery plans $[15,16]$. The accuracy can be increased further by simultaneous MEG/ EEG recording and analysis [17], because they have complementary sensitivity regarding source orientation and sensor/electrode coverage, which is useful for identification of artifacts and analysis of epileptic activity of deeper areas. A comparison of interictal MEG, EEG and combined EEG/MEG together with invasively recorded focal epileptic activities is shown in Fig. 1.

\section{Ictal MEG}

Among the studies listed in Table 1, compared to the 76-93\% frequency of interictal recordings during MEG data acquisition, there was a relatively low frequency of ictal MEG recordings (Table 1). The ictal MEG studies were initially performed only with few channels [22], later with multichannel hemispherical MEG recordings combined with foramen ovale electrodes [23] before whole head systems became available (Fig. 2). Further ictal MEG studies showed that at seizure onset the signal-to-noise ratio (SNR) for dipole analysis may be rather low or artifacts may obscure the seizure onset. However, in some successfully localized cases, the ictal source localization was demonstrated to be superior to interictal MEG with good correlation to invasively recognized seizure onsets [24, 25]. The ictal movements can be compensated by the development of continuous head localization and correction algorithms [26], thus providing more accurate ictal localizations.

Fujiwara et al. [27] applied different localization algorithms in addition to the classical dipole approach. Seizure onsets were defined by means of short-time fourier transform (STFT), according to the study by Yagyu et al. [28]. The results showed concordant ictal MEG onset source localization and interictal MEG discharge source localizations in the same lobe, and the ictal localizations are closer than the interictal to the seizure onset zone (SOZ) defined by invasive seizure onset. Moreover, the ictal MEG provides clear unilateral source localizations even if interictal MEG spikes are bilateral or missing, and shows better concordance with intercerebral EEG of the SOZ at the sub-lobar level than the interictal MEG. The interictal MEG discharges are useful for lobar localizations but tend to show a wider distribution.

Ictal MEG has also been evaluated by Medvedovsky et al. [20] using extended recording durations. The median time to the first recorded seizure was $5.7 \mathrm{~h}$, range from a few minutes to $40 \mathrm{~h}$ (on several days, only daytime seizures). A comparison in twelve patients showed

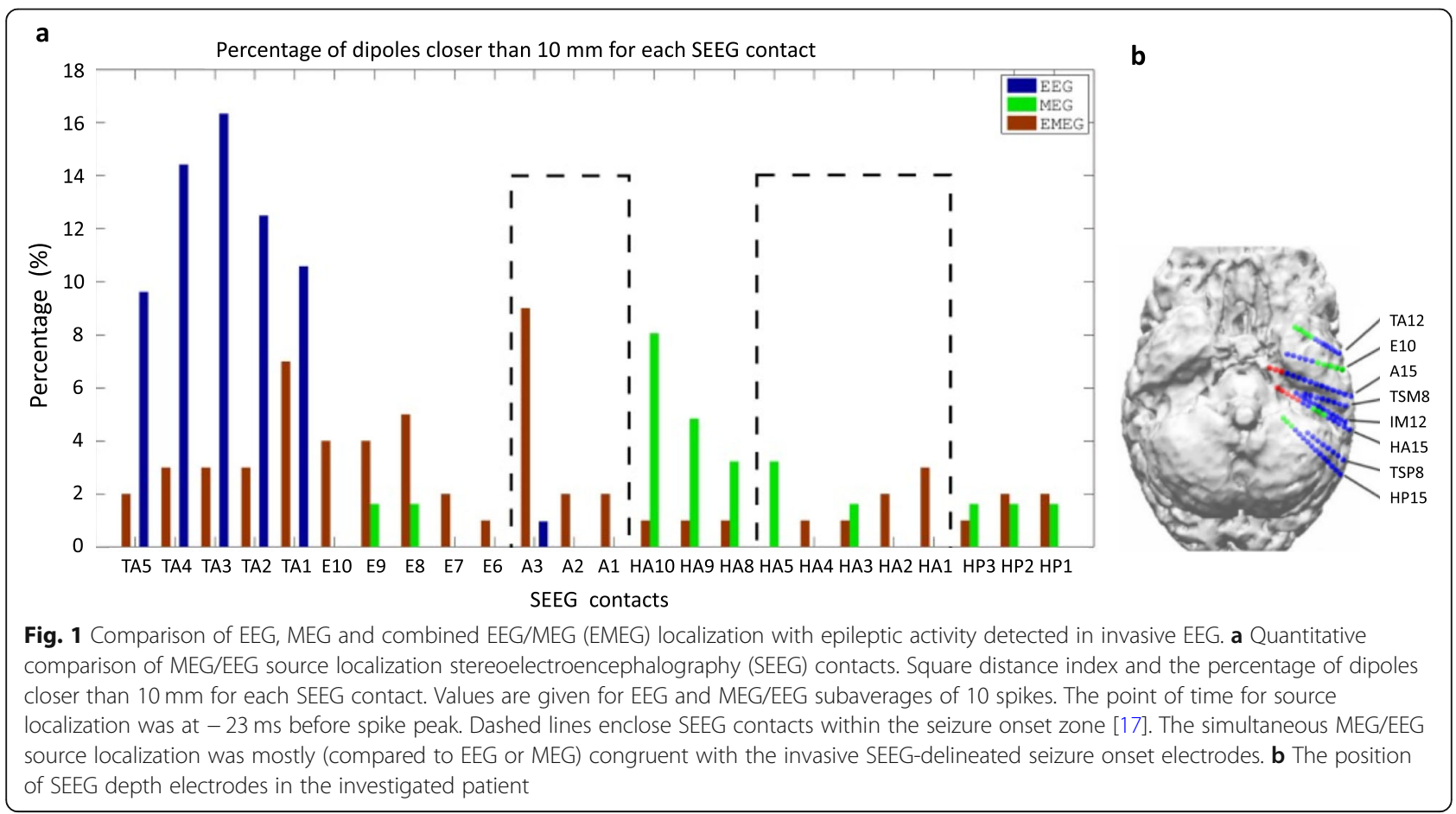


Table 1 Percentage of ictal recordings in different studies and average recording times

\begin{tabular}{llllll}
\hline Authors & Year & $\begin{array}{l}\text { Average recording } \\
\text { time }\end{array}$ & $\begin{array}{l}\text { No. of patients with seizures during MEG } \\
\text { recordings (i.e., ictal recordings) }\end{array}$ & $\begin{array}{l}\text { Total No. of } \\
\text { patients recorded }\end{array}$ & $\begin{array}{l}\text { Percentage of } \\
\text { ictal recordings }\end{array}$ \\
\hline Stefan [15] & 2003 & $30 \mathrm{~min}$ & 31 & 455 & $7 \%$ \\
Assaf [18] & 2003 & $120 \mathrm{~min}$ & 14 & 57 & $24 \%$ \\
Alkawadri [19] & 2018 & $51 \mathrm{~min}$ & 44 & 377 & $12 \%$ \\
Medvedovsky [20] & 2012 & $5.7 \mathrm{~h}$ & 47 & 246 & $19 \%$ \\
Ramajunam [21] & 2017 & $90 \mathrm{~min}$ & 40 & 310 & $12.9 \%$ \\
Velmurugan [2] & 2018 & $120 \mathrm{~min}$ & 67 & 691 & $10 \%$ \\
\hline
\end{tabular}

that the ictal data had a high sensitivity of 0.96 and a specificity of 0.9 for the SOZ on a lobar level while the interictal data had a sensitivity of 0.95 , but a much lower specificity of 0.75 . The positive predictive value (PPV) for the SOZ in dorsolateral areas was 0.765 . and for deeper SOZ was 0.786. The negative predictive value (NPV) for the dorsolateral SOZ was 0.625 and for deeper $\mathrm{SOZ}$ was 0.692 . The PPV for all surfaces was 0.774 and the NPV was 0.655.

The use of MEG has been described in some case reports to evaluate patients with non-convulsive status epilepticus [29, 30]. Figure 3 shows one example.

A 31 year old pharmacoresistent female patient with non-convulsive status epilepticus (NCSE) (open eyes, not able to comply to easy challenges, but able to count and walk without recalling her own activities) EEG showed continuous sharp waves bitemporo-occipital left accentuated. Magnetic source imaging (MSI) revealed focal epileptic activity in left temporal region (infrasylvic, at the posterior portions of the superior and medial temporal gyri and posterior to angular gyrus). The ictal MEG localization was confirmed by invasive presurgical localization [30]. Recordings during NCSE still are rare. A personal observation concerns a female 68 year old patient with pharmacoresistent focal aware and unaware seizures. Some years ago a parietal meningioma left was removed without seizure control. The patient was referred because of status aphasicus over weeks. Because of worse health

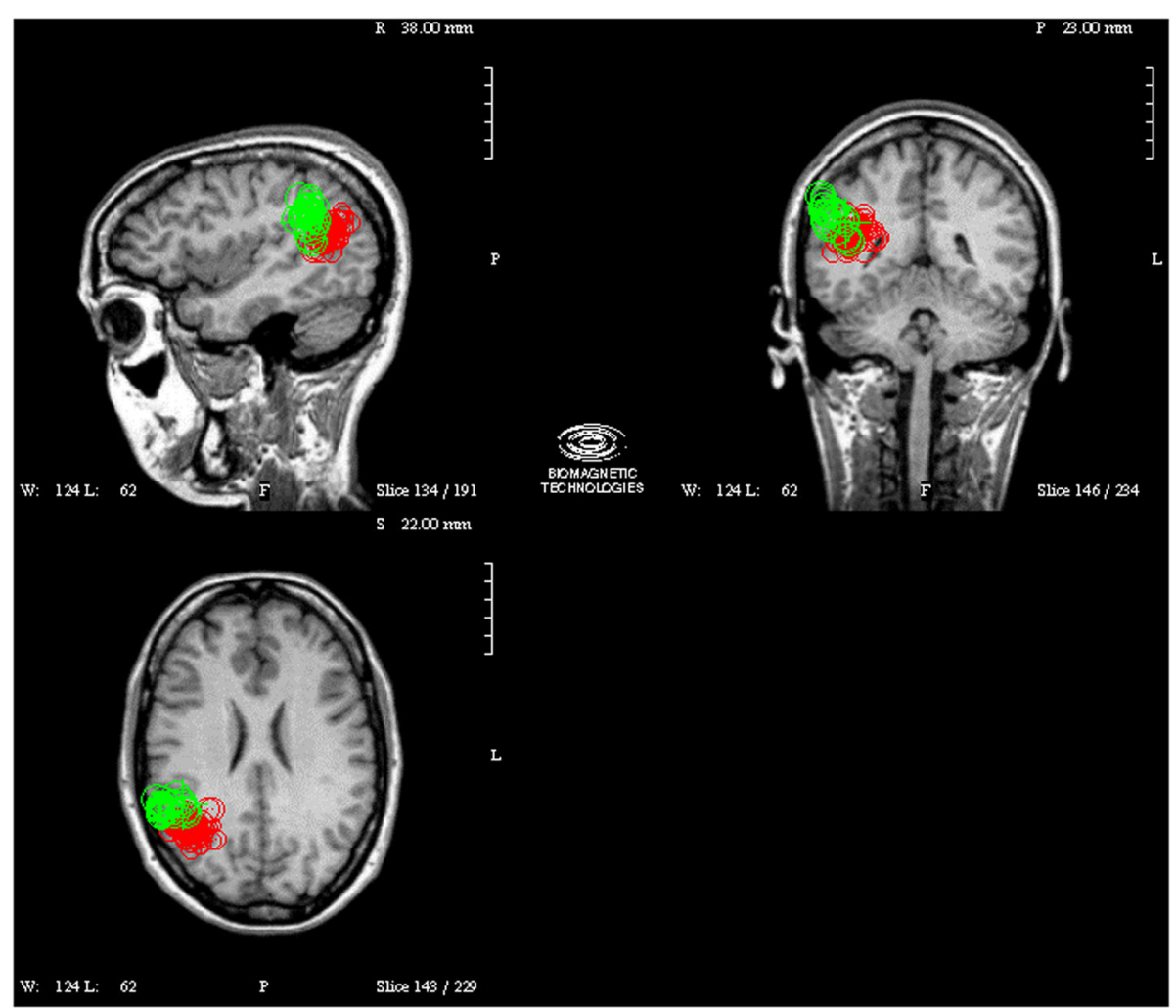

Fig. 2 Interictal and ictal magnetic source imaging (MSI) localizations in a patient with parietal focal cortical dysplasia (FCD) 2 (green: ictal, red: interictal) 


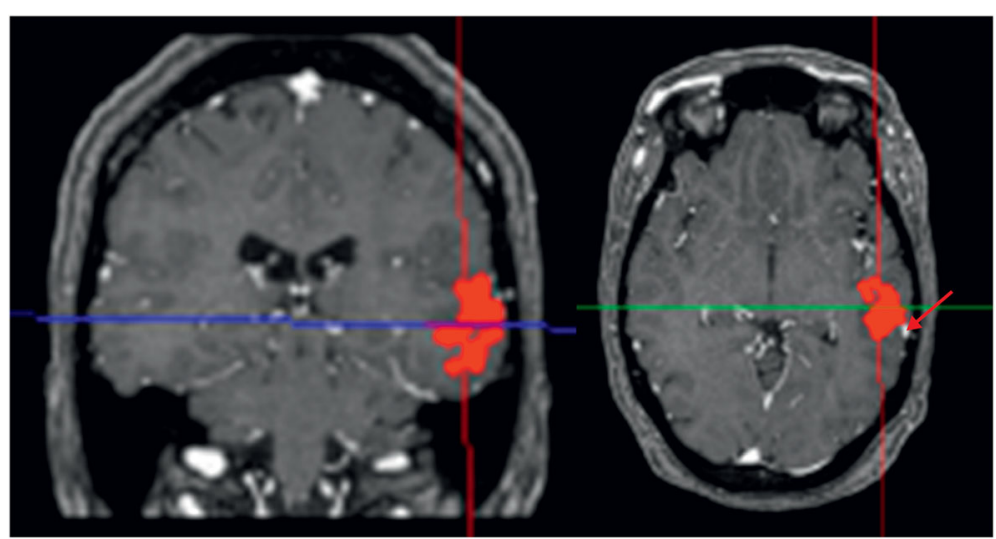

Fig. 3 Recordings during non-convulsive status epilepticus delineated a temporal lobe origin in a patient with unremarkable magnetic source imaging (MRI) [30]

condition no invasive recording for planning epilepsy surgery was possible. Ictal MEG during NCSE revealed focal epileptic activity adjacent to the previous menigioma resection volume. An MEG guided resective epilepsy surgery controlled the NCSE (Stefan, $\mathrm{H}$ personal observation).

In refractory status epilepticus [29] ictal MEG spike sources (MEGSSs) were localized in the right rolandic region (1 patient) and right temporal region (1 patient). Interictal MEG revealed unilateral clustered MEGSSs in four patients and bilateral (1 patient). Ictal-onset EEG findings were localized to one region in three patients and two regions in the other two patients. In all five patients, interictal discharges were widespread involving over two lobes ( 2 patients) or three lobes (3 patients). Suppression burst pattern was detected in one patient. Treatment was performed by cortical excision in two patients (2 patients), hemispherectomy in one and anterior temporal lobectomy in two patients. Two patients became seizure free, the other three patients experienced residual seizures. MEG showed clustered MEGSSs during the refractory status epilepticus (RSE) in the preexisting epilepsy patients and in an early time window in the acute symptomatic RSE patients. The complete resection of clustered MEGSSs can control refractory status epilepticus and possibly lead to a seizure free outcome.

A study by Alkawadri et al. [19] comparing interictal vs ictal MEG vs EEG reported that in 44 ictal MEGs, equivalent current dipole (ECD) analysis was possible in 29 patients (66\%), of whom 8 had no clear interictal discharges in either MEG or EEG. Lobar concordance between ictal and interictal dipoles was seen in all the remaining 21 cases, in whom interictal activity was detected. Sub-lobar concordance was observed in 18 cases (86\%). Two patients showed clear MEG ictal patterns but with no ictal EEG changes, whereas all the cases showing ictal EEG activity also displayed MEG patterns.

In addition to equivalent dipole analysis, other approaches of source localization can also be used, such as minimum norm estimate (MNE), rhythm-based analysis or gradient magnetic-field-topography (GMFT). Exemplary studies comparing interictal and ictal MEG analysis with dipole and multiple frequency band analysis [28] are illustrated in Fig. 4.

Jeong et al. [31] analyzed data from 13 patients with focal drug-resistant epilepsies, of whom 6 patients had normal magnetic resonance imaging (MRI), and 8 received preoperative invasive evaluation. All patients underwent epilepsy surgery with a mean postoperative follow-up of 3.98 years and had seizure outcomes of International League Againt Epilepsy (ILAE) 1 in 9 patients, and 3-6 in the remainder. The authors used sLORETA to analyze different frequency bands in several seconds of preictal data. Then compared the results to the resection cavity in postoperative MRI. Of the 9 seizure free patients, 7 showed sublobar concordance with the resection in gamma activity in a 10-s window before the seizure onset, three of whom had a normal MRI.

In five patients, interictal MEG yielded multilobar localizations, including two with bilateral findings, whereas ictal MEG provided sublobar concordance with the resection in three of these.

Badier et al. [32] have compared different ictal MEG localization approaches (linearly constrained minimum variance [LCMV] beamformer and dipoles) with regard to their ability to localize the epileptogenic zone, as determined by stereoelectroencephalography (SEEG) epileptogenicity index calculations. They found that while both methods could be applied successfully, LCMV was superior to the dipole localization. 

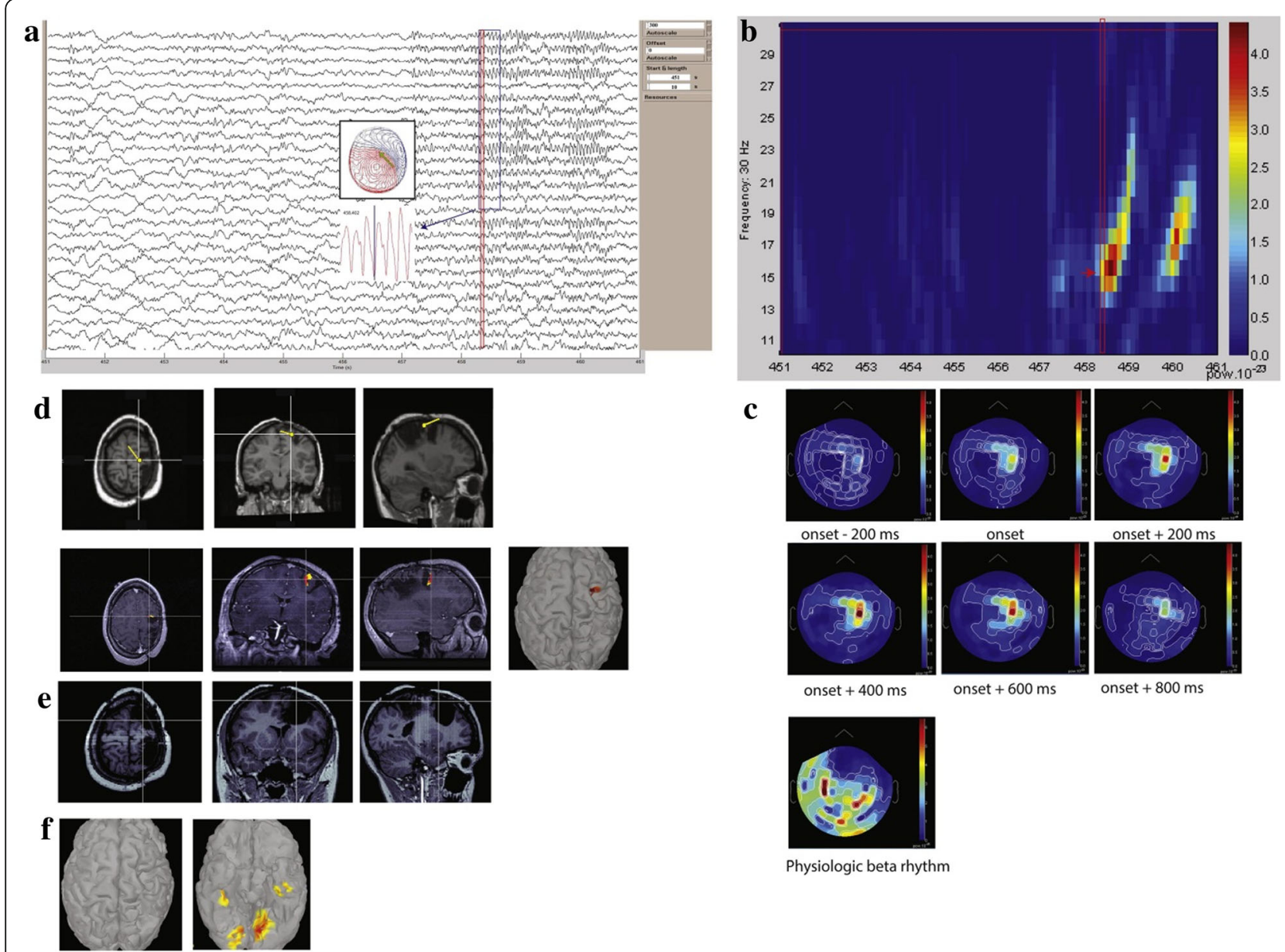

c
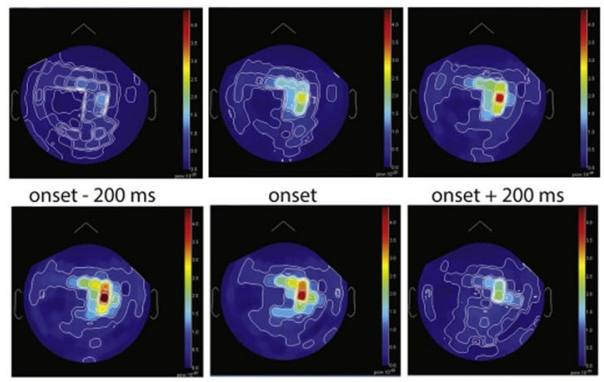

onset

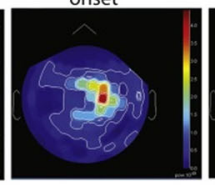

onset $+200 \mathrm{~ms}$

onset $+400 \mathrm{~ms}$

onset $+600 \mathrm{~ms}$

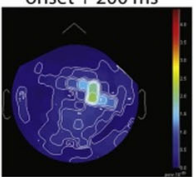

onset $+800 \mathrm{~ms}$

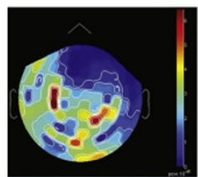

Physiologic beta rhythm

Fig. 4 Ictal MEG localization, comparison of minimum norm estimation (MNE) with FCD [28]. a MEG at time of seizure onset (arrow). b Morlet wave transformation. c Mapping of current density of the narrow band identified in $\mathbf{b}$. $\mathbf{d}$ Localization in the precentral gyrus by equivalent current dipole (ECD) analysis (upper row), and localization in the anterior edge of the prior resection ( $21.8 \mathrm{~mm}$ to ECD) by L2 MNE solution (lower row). e Postsurgical resection of the area delineated by L2-MNE narrow band. The MNE solution was in the resection cavity. $\mathbf{f} L 2-M N E$ solution, the ECD localization was $21.8 \mathrm{~mm}$ more posterior. Only the MNE localization was within the resection cavitiy

Pellegrino et al. [33] utilized wavelet-based maximum entropy on the mean (wMEM) to localize 46 MEG or EEG seizures in 13 patients. The results showed a generally high concordance between ictal and interictal findings. Ictal MEG was concordant on a sublobar level with the invasively identified SOZ in 10 of 11 patients, in whom this information was available. Ictal EEG localization showed sublobar concordance in 6 of 8 patients. Considering all individual seizures, concordance rates were similar for MEG (26/29 seizures) and EEG (9/ 14). The sublobar differences between ictal and interictal findings did not reach statistical significance. However, the rate of ictal/interictal concordance for MEG was better than that for EEG (90.32\% vs 66.67\%) and the interictal localizations were closer to the invasively determined seizure onset.

Shirouzu et al. [34] analyzed ictal MEG in patients with neocortical epilepsy. In 13 patients, ictal events were recorded during preoperative MEG. ECD estimation and GMFT were used to detect and localize the ictal MEG onset. Results were compared with the ictal onset zone (IOZ) derived from invasive EEG and the resection. GMFT detected and localized the ictal MEG onset in all patients, whereas ECD estimation showed localized ECDs in only two. The delineation of GMFT was concordant with the invasive localized $\mathrm{SOZ}$ at gyral level in 10 of 12 patients (83.3\%). The detectability and precision of the delineation of ictal MEG activity by GMFT were significantly superior to those of ECD $(P<0.05$ and $P<0.01)$. Complete resection of the IOZ in the concordant group provided seizure freedom in 3 patients, whereas seizures remained in 9 patients who had incomplete resections.

Can ictal MEG obviate the need for phase II monitoring in People with drug-refractory epilepsy? A prospective observational study tried to answer this question [21]. In that 
study ictal MEG was recorded in 40 of 310 patients with drug refractory epilepsy (12.9\%). A focal ECD source localization was available in 32 of them $(80 \%)$. The difference between numbers of patients cleared for surgery with and without ictal MEG data was statistically significant $(P=0.0044)$. The ictal MEG influenced decisions regarding the possibility of surgery in 9 and converted decisions on phase II monitoring (electrocordicographic) ECoGguided lesionectomy in 11 patients. Ictal-MEG helped to convert drug-resistant epilepsy patients unsuitable for surgery or planned for phase II monitoring into candidates for surgery and resulted in favorable outcomes in those who were operated.

Selection of brain regions for ictal MEG recordings has to take into account ictal semiology especially if no whole head MEG recording apparatus is available. Otherwise, there is no evidence that the sensitivity of MEG is different for ictal compared to interictal activity. Therefore, especially neocortical areas would be accessible. In addition, also based on the evidence from interictal data, patients with large or multiple lesions, skull defects, asymmetries and complex activity could potentially benefit from MEG recordings also in the interictal case.

In a prospective study of 11 patients with ictal MEG recordings a total of 31 seizures was recorded with EEG and MEG. Ictal MEG turned out positive in 25 of 31 seizures (80.6\%) [35]. These findings indicated that earlyphase source analysis of interictal and ictal discharges will produce high density EEG (HDEEG)-MEG source solutions that better guide and limit reliance on invasive intracranial monitoring in the pre-surgical diagnosis. Advantages and disadvantages of both interictal and ictal recording techniques are discussed. For the use of combined HDEEG/MEG or separate MEG and HDEEG analysis, the role of different head models have to be taken into account. For combined HDEEG/MEG analysis head volume conduction effects have to be modeled accordingly before a simultaneous analysis can be recommended. Aydin et al. 2015 [17] used individually calibrated 6-compartment finite element model (FEM) forward modeling to leverage the complementary information in EEG and MEG. In this process, the conductivity of the skull compartment was individually calibrated, because variability in skull conductivity is large. It was shown that it is the most important conductivity parameter for the EEG, while it has nearly no influence on the MEG forward modeling [36].

\section{Synopsis of interictal and ictal magnetic source imaging studies}

A meta-analysis of published ictal MEG studies in 238 cases revealed 146 patients with ictal and interictal epileptic activity during MEG recording. On a lobar level, ictal and interictal localizations were concordant, i.e. providing the same localization in $84 \%$. Information regarding concordance on a sublobar level was available in 105 patients and amounted to $73 \%$. In non-concordant cases, interictal localizations usually overlapped with the ictal results, but had more-extended distribution or included additional remote localizations. The comparison of lobar or sublobar concordance between interictal and ictal MEG is summarized in Table 2.

\section{Discussion}

Current studies have suggested that ictal MEG can provide additional and useful information in some cases. While ictal and interictal localizations show a high degree of concordance, ictal MEG has increased specificity for the invasively determined SOZ. In many of the studies, interictal localizations are usually overlapping, but show a more extended distribution over neighboring areas and sometimes also remote localizations. When interictal MEG recordings have normal or unclear results, ictal MEG localizes correctly in some cases.

The ictal MEG recordings can be facilitated by some developments. For example, prolonged video-MEG/EEG increase the probabilities to record and identify seizures [51]. Movement compensation [26, 52] and the projection of recorded data to a standard virtual MEG helmet [53] enable the correction of (limited) patient movement during a seizure and increases the percentage of usable MEG recordings. Analytically, the application of STFT $[27,28,31]$ for identification of seizure onsets, and the use of distributed source localization approaches [32, 34], especially frequency-based methods [31], seem to improve the localization accuracy in comparison to ECD approaches. Regarding MEG ictal focus localization, there is very little data on specific aspect of localization methodology in lesional subgroups. However, the specific type of lesion will of course only impact source analysis if the generated epileptic activity exhibits any special, potentially limiting features. In ictal source analysis, one of such feature would be fast spread to involve larger areas. In this case, dipole localizations are more susceptible to mislocalization as the assumption is of course that the activity is generated by a single focal source. Distributed source models may be better suited to handle this or suggest propagation if their results deviate from dipole localization. Frequency based source analysis, e.g. using dynamic imaging of coherent sources (DICS), is especially useful if the the seizure exhibits a stable oscillatory component during onset. Then such methods would allow to focus on this while other, e.g. artifact components will have minimal impact. Lesional characteristics may show influence due to the location. E.g. bottom-of-sulcus focal cortical dysplasias (FCDs) may show activity with a dominant radial component, which is not recorded by MEG. Activity may thus 
Table 2 Concordance of interictal and ictal magnetic source imaging (MSI) on lobar and sublobar levels

\begin{tabular}{|c|c|c|c|c|c|c|}
\hline \multirow[t]{2}{*}{ Author } & \multirow[t]{2}{*}{ Year } & \multicolumn{2}{|c|}{ Concordant ictal/interictal } & \multicolumn{2}{|l|}{ Total } & \multirow[t]{2}{*}{ Remarks } \\
\hline & & lobar & sublobar & lobar information & sublobar information & \\
\hline Sutherling [22] & 1987 & 2 & $\mathrm{NsA}$ & 2 & $\mathrm{NA}$ & \\
\hline Stefan [23] & 1992 & 1 & NA & 1 & 1 & \\
\hline Ishibashi [37] & 1998 & 1 & NA & 1 & NA & \\
\hline Kirchberger [38] & 1998 & 2 & 2 & 2 & 2 & \\
\hline Ko [39] & 1998 & 2 & 2 & 2 & 2 & \\
\hline Bowyer [40] & 2000 & 1 & 1 & 1 & 1 & \\
\hline Shiraish [41] & 2001 & 4 & NA & 4 & NA & \\
\hline Eliashev [24] & 2002 & 4 & NA & 5 & NA & \\
\hline Tilz [25] & 2002 & 5 & NA & 6 & NA & \\
\hline Oishi [42] & 2002 & 1 & 1 & 1 & 1 & \\
\hline Assaf [18] & 2003 & 2 & 2 & 2 & 2 & \\
\hline Tang [43] & 2003 & 5 & 5 & 5 & 5 & \\
\hline Yoshinaga [44] & 2004 & 2 & 1 & 2 & 2 & \\
\hline Tayah [45] & 2006 & 2 & 1 & 3 & 3 & \\
\hline Vitkainen [46] & 2009 & 2 & NA & 2 & NA & \\
\hline Xiang [47] & 2010 & 4 & 3 & 4 & 4 & $\mathrm{HFO}$ \\
\hline Yagyu [28] & 2010 & 3 & 3 & 3 & 3 & Frequency \\
\hline Kakisaka [48] & 2011 & 1 & NA & 2 & NA & \\
\hline Medvedovsky [20] & 2012 & 7 & 6 & 12 & 12 & \\
\hline Schmitt \& Rampp [30] & 2012 & 1 & 1 & 1 & NA & \\
\hline Alkawadri [19] & 2018 & 21 & 18 & 21 & 21 & Frequency \\
\hline Fujiwara [27] & 2012 & 4 & 0 & 8 & 8 & Frequency \\
\hline Jeong [31] & 2016 & 9 & 8 & 13 & 13 & Frequency \\
\hline Pellegrino [33] & 2016 & 13 & 13 & 11 & 13 & WMEM \\
\hline Shirozu [34] & 2017 & 12 & 10 & 12 & 12 & GMFT \\
\hline Velmurugan [49] & 2018 & 12 & NA & 20 & NA & $\mathrm{HFO}$ \\
\hline \multirow[t]{2}{*}{ Total } & & 123 & 77 & 146 & 105 & \\
\hline & & $84 \%$ & $73 \%$ & & & \\
\hline Not included & & & & & & Reason \\
\hline Badier [32] & 2016 & & & 6 & & No interictal information \\
\hline Koptelova [50] & 2018 & & & 7 & & Extended activity \\
\hline Ramajunam [21] & 2017 & 19 & 9 & 32 & & Indirect information \\
\hline
\end{tabular}

NA no information available, HFO high frequency oscillation, wMEM wavelet-based maximum entropy on the mean, GMFT gardient magnetic field topography

require slight propagation into the sulcal walls to generate a signal than is visible to MEG. However, our experience [54] shows that this may cause only a minor offset even in the interictal case. It has to be noted however, that these points of discussion are based on localization theory and interictal findings due to the lack of ictal data. More studies would be required to evaluate such specialized aspects.

However, the ictal MEG recordings have some limitations. First of all, the overall probability to record seizures during a routine MEG session can be as low as 7-
24\% (Table 1). Although recording durations of more than about $60 \mathrm{~min}$ may increase the probability to 19 $25 \%$, it may be more difficult to achieve the necessary logistics and the patients' comfort may be impaired. Second, while some patient movements during seizures can be compensated, larger movement remains a source of error due the associated artifacts. In extreme cases, patients may completely or partially slip out of the dewar, making it impossible to record anymore. Even if such problems do not occur, the SNR of ictal activity may be low at the seizure onset, resulting in localization issues. 
Frequency-based methods, such as STFT [27, 28] or multiple-frequency-band source localization [31] may be helpful in such circumstances. Furthermore, general limitations of MEG, such as artifacts due to metal implants, are of course also relevant for ictal recordings.

Ictal MEG recording in the future may be considerably improved by optically pumped magnetometer (OPM). Since this new type of sensor is directly mounted to the surface of the head, sensitivity is improved and the problem of head movement is considerably reduced. Furthermore, OPM sensors could be placed over the basal areas of the head, improving coverage of temporal areas, a limitation of current MEG systems.

A limitation of our review and, specifically, the evaluation of ictal and interictal results is the lack of standard reporting of localization results regarding brain regions and the different recording and analytical techniques (e.g. head movement compensation, dipole or frequency band based source localization, seizure types). Furthermore, the reviewed literature spanned approximately three decades. While technical and analytical advancements have facilitated ictal recordings and analysis, the same also occurs for interictal recordings. The sublobar concordance rate may be higher than $73 \%$, if up-to-date methods and procedures are applied. A recent EEG study showed that localizations of the spike onset can be in a different sublobar region than localizations of the peak in up to $40 \%$ [55]. Comparison to the reference standard of the decision of a multidisciplinary patient management conference ensures that the difference is not only caused by a lower SNR. Localizations of early vs late components may thus already explain a large portion of the differences of ictal vs interictal results.

Due to the technical and logistical requirements, special indications for attempting ictal recordings are required (Table 3). In such specific patient populations, simultaneous prolonged MEG/EEG recordings should be

Table 3 Indications for ictal MEG applications

\begin{tabular}{ll}
\hline Indications & Reference \\
\hline $\begin{array}{l}\text { High likelihood of seizure recording } \\
\text { no spikes }\end{array}$ & Medvedovsky et al., 2012 [20] \\
$\begin{array}{l}\text { EEG and MRI unclear, MEG interictal } \\
\text { lobar }\end{array}$ & Oishi et al., 2002 [40] \\
$\begin{array}{l}\text { Pharmacoresistent status } \\
\text { nonconvulsivus }\end{array}$ & Schmitt and Rampp, 2012 [30] \\
$\begin{array}{l}\text { Skull defects } \\
\text { Suspected frontobasal, mesial occipital } \\
\text { or insular localization }\end{array}$ & Ramanumam et al., 2017 [21] \\
$\begin{array}{l}\text { Noninvasive classification of system } \\
\text { epilepsies }\end{array}$ & Sakurai et al., 2010 [57] \\
\hline
\end{tabular}

established in order to further enhance the precision of noninvasive source localization for presurgical evaluation.

\section{Conclusion}

Ictal MEG has increased specificity for the invasively determined SOZ. In many of the studies, interictal localizations are usually overlapping but show a more extended distribution over neighboring areas and sometimes also remote localizations. When interictal MEG recordings have normal or unclear results ictal MEG localizes correctly in some cases. Special indications, technical and logistical requirements for attempting ictal recordings are required. In such specific patient populations, simultaneous prolonged MEG/EEG recordings should be established in order to further enhance the precision of noninvasive source localization for presurgical evaluation. Ictal MEG recording in the future may be considerably improved by OPM.

\section{Abbreviations}

DICS: Dynamic imaging of coherent sources; ECD: Equivalent current dipole; FCD: Focal cortical dysplasia; FEM: Finite element model; FLE: Frontal lobe epilepsy; GMFT: Gradient magnetic field topography; ILAE: International League Against Epilepsy; IOZ: Ictal onset zone; LCMV: Lineary constrained minimum vatiance; MEG: Magnetoencephalography; MNE: Minimum norm estimate; MRI: Magnetic resonance imaging; MSI: Magnetic source imaging; NCSE: Non-convulsive status epilepticus; NPV: Negative predictive value; OPM: Optically pumped magnometer; PPV: Positive predictive value; RSE: Refractory status epilepticus; SEEG: Stereoelectroencephalogram; SNR: Signal to noise ratio; SOZ: Seizure onset zone; STFT: Short-time fourier transform; wMEM: Wavelet-based maximum entropy on the mean

\section{Acknowledgements}

Not appilcable for that section.

\section{Authors' informations}

Dr. S. Rampp has been seen and informed of all data. He fully approved to the content of the manuscript.

Authors' contributions

The author(s) read and approved the final manuscript.

\section{Funding}

Financial support for this study was received from DFG grants.

Availability of data and materials

Clinic of Neurology - Epilepsy Center, Department of Neurosurgery, University Hospital Erlangen.

Ethics approval and consent to participate

Not applicable for that section.

Consent for publication

Not applicable for that section.

Competing interests

$H$. Stefan received DFG grants, honoraria and travel reimbursement from Elekta Oy, Helsinki, Finland; S. Rampp serves as a consultant for Elekta Oy, Helsinki, Finland. There is no conflict of interest concerning the content of this paper.

\section{Author details}

${ }^{1}$ Department of Neurology - Biomagnetism, University Hospital Erlangen, 6, Schabachanlage, 91054 Erlangen, Germany. ${ }^{2}$ Department of Neurosurgery, University Hospital Erlangen, 6, Schabachanlage, Erlangen, Germany. 
Received: 29 April 2020 Accepted: 30 June 2020 Published online: 04 August 2020

\section{References}

1. Téllez-Zenteno JF, Dhar R, Wiebe S. Long-term seizure outcomes following epilepsy surgery: a systematic review and meta-analysis. Brain. 2005;128(5): 1188-98.

2. Blumcke I, Spreafico R, Haaker G, Coras R, Kobow K, Bien CG, et al. EEBB consortium. Histopathological findings in brain tissue obtained during epilepsy surgery. N Engl J Med. 2017;377(17):1648-56.

3. Mu J, Rampp S, Carrette E, Roessler K, Sommer B, Schmitt FC, et al. Clinical relevance of source location in frontal lobe epilepsy and prediction of postoperative long-term outcome. Seizure. 2014;23(7):553-9.

4. Vadera S, Burgess R, Gonzalez-Martinez J. Concomitant use of stereoele ctroencephalography (SEEG) and magnetoencephalographic (MEG) in the surgical treatment of refractory focal epilepsy. Clin Neurol Neurosurg. 2014; 122:9-11.

5. Hufnagel A, Dumpelmann M, Zentner J, Schijns O, Elger CE. Clinical relevance of quantified intracranial interictal spike activity in presurgical evaluation of epilepsy. Epilepsia. 2000:41(4):467-78.

6. De Tiège $X$, Lundqvist D, Beniczky S, Seri S, Paetau R. Current clinical magnetoencephalography practice across Europe: are we closer to use MEG as an established clinical tool? Seizure. 2017;50:53-9.

7. Minassian BA, Otsubo H, Weiss S, Elliott I, Rutka JT, Snead OC. Magnetoencephalographic localization in pediatric epilepsy surgery: comparison with invasive intracranial electroencephalography. Ann Neurol. 1999;46(4):627-33.

8. Oishi M, Kameyama S, Masuda H, Tohyama J, Kanazawa O, Sasagawa M, et al. Single and multiple clusters of magnetoencephalographic dipoles in neocortical epilepsy: significance in characterizing the epileptogenic zone. Epilepsia. 2006;47(2):355-64.

9. Rheims S, Jung J, Ryvlin P. Combination of PET and magnetoencephalography in the presurgical assessment of MRI-negative epilepsy. Front Neurol. 2013;4:188.

10. Seo JH, Holland K, Rose D, Rozhkov L, Fujiwara H, Byars A, et al. Multimodality imaging in the surgical treatment of children with nonlesional epilepsy. Neurology. 2011;76(1):41-8

11. Vadera S, Jehi L, Burgess RC, Shea K, Alexopoulos AV, Mosher J, et al. Correlation between magnetoencephalography-based "clusterectomy" and postoperative seizure freedom. Neurosurg Focus. 2013;34(6):E9.

12. Wilenius J, Medvedovsky M, Gaily E, Metsähonkala L, Mäkelä JP, Paetau A, et al. Interictal MEG reveals focal cortical dysplasias: special focus on patients with no visible MRI lesions. Epilepsy Res. 2013; 105(3):337-48.

13. Nissen IA, Stam CJ, Reijneveld JC, van Straatenb IE, Hendriks FJ, Baayen JC, et al. Identifying the epileptogenic zone in interictal resting-state MEG source-space networks. Epilepsia. 2017;58(1):137-48.

14. Englot DJ, Hinkley LB, Kort NS, Imber BS, Mizuiri D, Honma SM, et al. Global and regional functional connectivity maps of neural oscillation in focal epilepsy. Brain. 2015;138(Pt 8):2249-62.

15. Stefan H, Hummel C, Scheler G, Genow A, Druschky K, Tilz C, et al. Magentic brain source imaging of focal epileptic activity: a synopsis of 455 cases. Brain. 2003;126(11):2396-405.

16. Stefan H, Trinka E. Magnetoencephalography (MEG): Past, current and future perspectives for improved differentiation and treatment of epilepsies. Seizure. 2017;(44):121-4.

17. Aydin Ü, Vorwerk J, Dümpelmann $M$, Küpper $P$, Kugel $H$, Heers $M$, et al. Combined EEG/MEG can outperform single modality EEG or MEG source reconstruction in presurgical epilepsy diagnosis. PLoS One. 2015;10(3): e0118753.

18. Asaff BA, Karkar KM, Laxer KD, Garcia PA, Austin EJ, et al. Ictal magnetoencephalo-graphy in temporal and extemporal ,loobe epilepsy. Epilepsia. 2003:44(10):1320-7.

19. Alkawadri R, Burgess RC, Kakisaka Y, Mosher JC, Alexopoulos AV. Assessment of the utility of ictal magnetoencephalography in the localization of the epileptic seizure onset zone. JAMA Neurol. 2018; 75(10):1264-72

20. Medvedovsky M, Taulu S, Gaily E, Metsähonkala E-L, Mäkela JP, Ekstein D, et al. Sensitivity and specificity of seizure-onset zone estimation by ictal magnetoencephalography. Epilepsia. 2012;53(9):1649-57.
21. Ramanujam B, Bharti K, Viswanathan V, Garg A, Tripathi M, Bal C, et al. Can ictal-MEG obviate the need for phase II monitoring in people with drugrefractory epilepsy? A prospective observational study. Seizure. 2017;45:17-23.

22. Sutherling WW, Crandall PH, Engel J, Darcey TM, Cahan LD, Barth DS. The magnetic field of complex partial seizures agrees with intracranial localizations. Ann Neurol. 1987;21(6):548-58.

23. Stefan $H$, Abraham-Fuchs $K$, Schneider S, Schüler P, Huk DJ. Multichannel MEG and EEG recordings of interctal and ictal epileptic activity in temporal lobe epilepsy. In: Bachmann K, Strfan H, Vieth J, editors. Biomagnetism: Principles, models and clinical research. Erlangen: Verlag Palm \& Enke; 1992. p. 48-9.

24. Eliashiv DS, Elsas SM, Squires K, Fried I, Engel J Jr. Ictal magnetic source imaging as a localizing tool in partial epilepsy. Neurology. 2002;59(10):1600-10

25. Tilz C, Hummel C, Kettenmann B, Stefan H. Ictal onset localization of epileptic seizures by magnetoencephalography. Acta Neurol Scand. 2002; 106(4):190-5.

26. Medvedovsky M, Taulu S, Bikmullina R, Paetau R. Artifact and head movement compensation in MEG. Neurol, Neurophysiol Neurosci. 2007;4.

27. Fujiwara H, Greiner HM, Hemasilpin N, Lee KH, Holland-Bouley K, Arthur T, et al. Ictal MEG onset source localization compared to intracranial EEG and outcome: improved epilepsy presurgical evaluation in pediatrics. Epilepsy Res. 2012;99(3):214-24

28. Yagyu K, Takeuchi F, Shiraishi H, Nakane S, Sueda K, Asahina N, et al. The applications of time-frequency analyses to ictal magnetoencephalography in neocortical epilepsy. Epilepsy Res. 2010;90(3):199-206.

29. Mohamed IS, Otsubo H, Donner E, Ochi A, Sharma R, Drake J, et al. Magnetoencephalography for surgical treatment of refractory status epilepticus. Acta Neurol Scand. 2007;186:29-36.

30. Schmitt FC, Rampp S. The lady from "no-man's-land". In: Stefan H, Chauvel $P$, Ben Menachem E, Guerrini R, editors. Case studies in epilepsy: common and uncommon presentations. 1st ed. Cambridge: Cambridge Universtiy Press; 2012. p. 88-92.

31. Jeong W, Kim JS, Chung CK. Usefulness of multiple frequency band source localizations in ictal MEG. Clin Neurophysiol. 2016;127(2):1049-56.

32. Badier JM, Bénar CG, Woodman M, Cruto C, Chauvel P, Bartolomei F, et al. Ictal magnetic source imaging in presurgical assessment. Brain Topogr. 2016:29(1):182-92.

33. Pellegrino G, Hedricj T, Rasheda C, Hall JA, Lina JM, Dubeau F, et al. Source loc alization of the sezizure onset zone from ictal EEG/MEG data. Hum Brain Mapping. 2016;37(7):2528-46.

34. Shirozu H, Hashizume A, Masuda H, Ito Y, Nakayama Y, Higashijima T, Kameyama S. Analysis of ictal magnetoencephalography using gradient magnetic-field topography (GMFT) in patiens with neocortical epilepsy. Clin Neurophysiol. 2017;128(8):1504-12.

35. Plummer C, Vogrin J, Wood W, Murphy M, Cook M, Liley D. Interictal and ictal slource localization for epilepsy surgery using high-density EEG with MEG: a prospective long term study. Brain. 2019;142(4):932-51.

36. Vorwerk J, Cho JH, Rampp S, Hamer H, Knösche T, et al. A guideline for head volume conductor modeling in EEG and MEG. Neuroimage. 2014;100: 590-607.

37. Ishibashi H, Moritoka T, Shigotogeto H, Fukui M. Three-dimensional localization of subclinical ictal activity by MEG. Surgl Neurol. 2010;89(2-3): 176-84.

38. Kirchberger K, Hummel C, Stefan H. Postoperative multichannel magnetoence-phalography in patients with recurrent seizures after epilepsy surgery. Acta Neurol Scand. 1998;98(1):1-7.

39. Ko D, Kufta C, Scaffidi D, Sato S. Source localization determined by MEG and EEG in temporal lobe epilepsy. Neurosurg. 1998:42(2):414-21.

40. Bowyer SM, Tepley N, Welch KM, Kato S, Barkley GL. Epileptic seizures localized by MEG in book of abstracts p 511 biomag; 2000.

41. Shiraishi H, Watanabe Y, Watanabe M, Inoue Y, Fujiwara I, Yagi K. Interictal and ictal MEG study in patients with medial frontal lobe epilepsy. Epilepsia. 2001:42(7):875-82.

42. Oishi M, Kameyama S, Morota N, Tomikawa M, Wachi M, Kakita A, et al. Fusiform gyrus epilepsy. The use of ictal MEG. J Neurosurg. 2002;97(1): 200-4.

43. Tang L, Mantle M, Ferrari $P$, Schiffbauer $H$, Rowley HA, Barbaro NM, et al. Consistency of interictal and ictal onset localization using MEG in patients with partial epilepsy. J Neurosurg. 2003;98(4):837-45.

44. Yoshinaga $H$, Ohtsuka $Y$, Watanabe $Y$, Watanabe $M$, Inutsuka $M$, Kitamura $Y$, et al. Ictal MEG in two children with partial seizures. Brain and Development. 2004;26(6):403-8. 
45. Tayah TF, Abou-Khalil B, Gilliam FG, Knowlton RC, Wushensky CA, Gallagher MJ. Musicogenic seizures can arise from multiple temporal lobe foci: intracranial EEG analysis of three patients. Epilepsia. 2006;47(8):1402-6.

46. Vitikainen AM, Lioumis P, Paetau R, Salli E, Komssi S, Metsahonkala L, et al. Combined use of non-invasive techniques for improved functional localization for a selected group of epilepsy surgery candidates. Neuroimage. 2009;45(2):342-8.

47. Xiang J, Wang Y, Chen Y, Liu Y, Kotechecha R, Huo X, et al. Noninvasive localization of epileptic zones with ictal high frequency neuromagnetic signals. J Neurosurg Pediatr. 2010;5(1):113-22.

48. Kakisaka Y, Gupta A, Wang ZI, Dubarry AS, Alexopoulos AV, Mosher JC, et al. Different cortical involvement pattern of generalized and localized spasms: a magnetoencephalo-graphy study. Epilepsy Behav. 2011;22(3):599-601.

49. Velmurugan J, Nagarajan SS, Mariyappa N, Ravi SG, Thennarasu K, MundlamuriRC RC, et al. Magnetoencephalograpic imaging of ictal highfrequency oscillation (80-200 Hz) in pharmalogically resistant focal epilepsy. Epilepsia. 2018:59(1):190-202.

50. Koptelova A, Bikumullina R, Medvedovsky M, Novikova S, Goloteev A, Grinenko O, et al. Ictal and interictal MFG in pediatric patients with tuberous sclerosis and drug resistant epilepsy. Epilepsy Res. 2018;140:162-5.

51. Zhdanov A, Wilenius J, Paetau R, Ahonen A, Mäkelä JP. Quantifying the contribution of video in combined video-magnetoencephalographic ictal recordings of epilepsy patients. Epilepsy Res. 2013;105(3):405-9.

52. Little G, Boe S, Bardouille T. Head movement compensation in real time magnetoencephalo-graphic recordings. MethodsX. 2014;1:275-82.

53. Medvedovsky M, Nenonen J, Koptelova A, Butorina A, Paetau R, Makela JP, et al. Virtual MEG helmet: computer simulation of an approach to neuromagnetic field sampling. IEEE J Biomed Health Inform. 2016;20(2):539-48.

54. Kasper B, Rössler K, Hamer H, Dörfler A, Blümcke I, et al. Coregistrating magnetic source and magnetic resonance imaging for epilepsy surgery in focal cortical dysplasia. Neuroimage Clin. 2018;19:487-96.

55. Măliia MD, Meritam P, Scherg M, Fabricius M, Rubboli G, Mîndruță l, et al. Epileptiform discharge propagation: analyzing spikes from the onset to the peak. Clin Neurophysiol. 2016;127(4):2127-33.

56. Alkawadri R, Krishan B, Kakisaka Y, Nair D, Mosher JC, Burges RC Alexopoulos AV. Localization of the ictal onset zone with MEG using minimum norm estimate of of a narrow band at seizure onset versus standard single current dipole modeling. Clin Neurophysiol. 2013;124(9): 1915-8.

57. Sakurai K, Takedya Y, Tanaka N, Kuriat H, Takeuchi F, et al. Generalized spikewave discharges involve a default mode network in patients with juvenile absence epilepsy: a MEG study. Epilepsy Res. 2010;89(2-3):176-84.

Ready to submit your research? Choose BMC and benefit from:

- fast, convenient online submission

- thorough peer review by experienced researchers in your field

- rapid publication on acceptance

- support for research data, including large and complex data types

- gold Open Access which fosters wider collaboration and increased citations

- maximum visibility for your research: over $100 \mathrm{M}$ website views per year

At $\mathrm{BMC}$, research is always in progress.

Learn more biomedcentral.com/submissions 